\title{
Armas culturais
}

\section{Brent Meersman}

\section{Sizwe Banzi morreu \\ (Sizwe Banzi est mort), \\ de Athol Fugard, \\ John Kani \\ e Winston Ntshona, \\ enc. Peter Brook, \\ Centre International de \\ Créations Theâtrales 2007 \\ (Pitcho Womba Konga e \\ Habib Dembélé), \\ fot. Mário del Curto.}

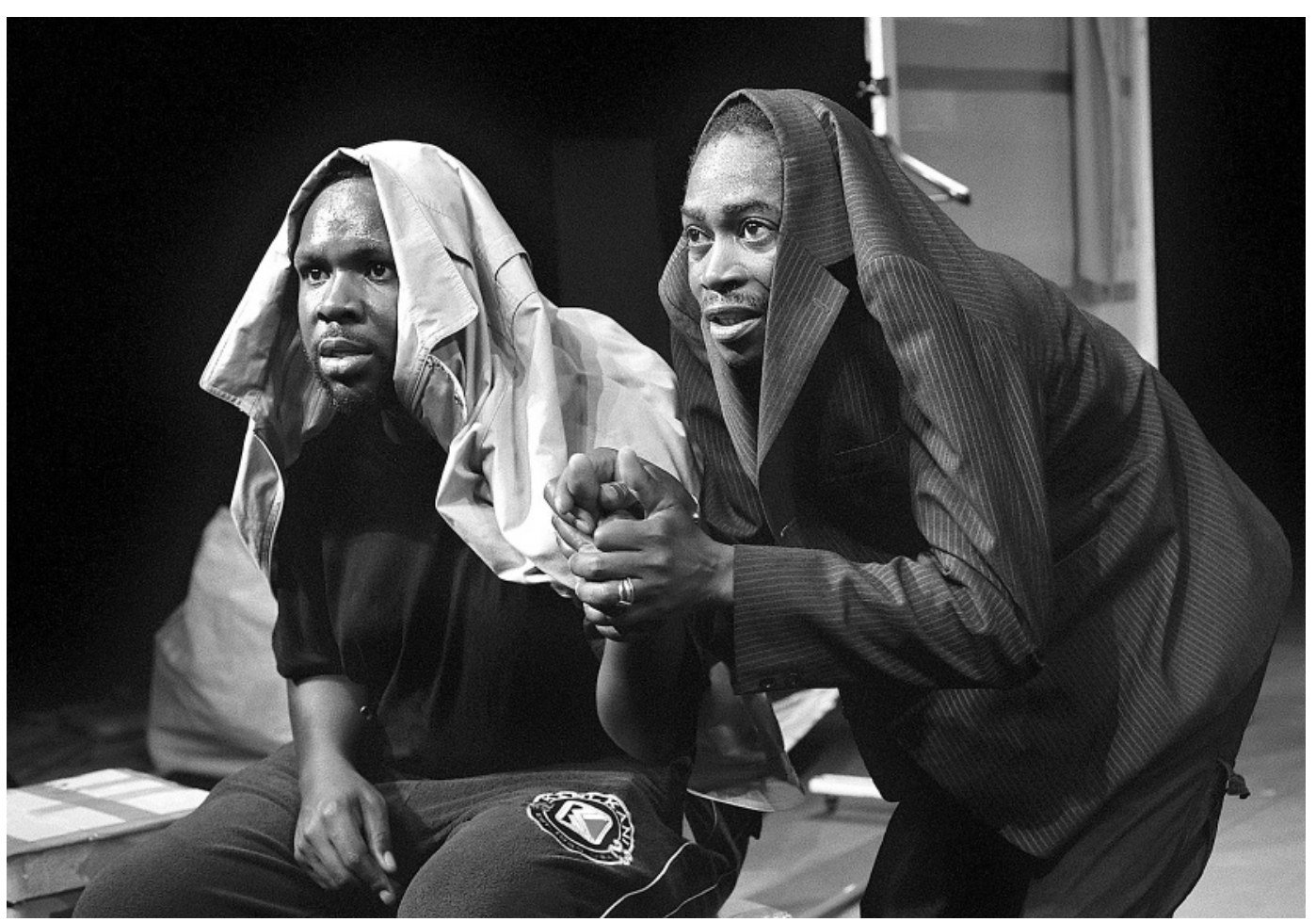

A violência, tal como a lança do guerreiro Aquiles, pode curar as feridas que infligiu, escreveu Jean-Paul Sartre na sua introdução a Os condenados da terra (Les damnés de la terre), um texto seminal em filosofia da libertação, de Frantz Fanon, o psicanalista das Índias Ocidentais. Infelizmente, em parte graças a Sartre, Fanon é muitas vezes caricaturado como um defensor da sanguinolência, em vez de ser considerado um filósofo que descreveu realisticamente os conflitos anti-coloniais na Argélia da década de 50 e, profeticamente, os que se seguiriam em toda a África. Refiro isto para, mais tarde, evitar ser colocado no mesmo banco dos réus que ele. Para citar Sartre:
[M]atar um europeu é matar dois coelhos com uma só cajadada, destruir um opressor e o homem que ele oprime ao mesmo tempo: o resultado é um homem morto e um homem livre; o sobrevivente sente, pela primeira vez, o solo nacional debaixo dos seus pés. (Sartre in Fanon 2004: Iv)

Fanon reconheceu que a "violência dos colonizados... unifica o povo" e, na sua qualidade de psicólogo, Fanon observava a libertação do eu através da destruição do opressor, a quebra do tabu... "A nível individual, a violência é uma força libertadora: liberta o colonizado do seu complexo de inferioridade, da sua atitude passiva e desesperada" (Fanon 2004: 51). É, por isso, com alguma suspeição que muitos de nós no mundo desenvolvido encaramos a palavra "humanismo", um termo filosófico de aparente delicadeza que durante séculos disfarçou as crueldades do racismo e da colonização. Fanon cita a peça lírica de Aimé Césaire E os cães calavam-se (Et les chiens se taisaient):

[E]le era o mestre... Eu entrei. És tu, disse ele, calmamente... Era de facto eu, disse-Ihe, o escravo bom, o escravo fiel, o escravo escravo, e subitamente os meus olhos eram duas baratas assustadas num dia de chuva... Dei o golpe, o sangue jorrou: é o único baptismo de que hoje em dia me recordo. (Césaire 1990)

Ou uma citação lacónica de uma outra peça, desta vez de Derek Walcott: "se queres descobrir a bela profundidade da tua negritude, negro, corta-Ihe a cabeça" (Walcott 1970).

0 que Fanon não aborda na consequência desta violência são as cicatrizes psicológicas que ela deixa no homem libertado, que, através da insurreição sangrenta, por vezes o assassínio indiscriminado de civis com bombas rudimentares e terror urbano, descobre que se rebaixou moralmente até ao nivel do seu opressor. E tem agora de 


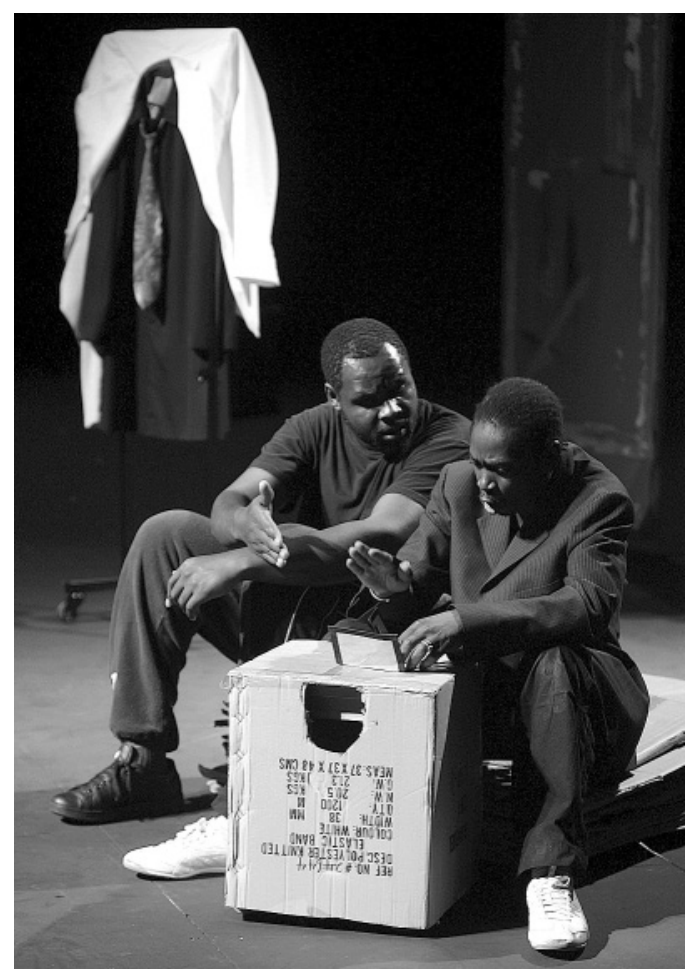

transportar consigo uma culpa adicional porque emergiu vitorioso com a história do seu lado.

$\mathrm{Na}$ África do Sul, lidamos com isto através da Comissão para a Verdade e Reconciliação, dirigida pelo Arcebispo Desmond Tutu, sobre a qual tem surgido uma enxurrada de peças ${ }^{1}$, romances, filmes e até uma cantata dramática. Os retratos da violência e da tortura politicamente motivada são, nestes contextos, feitos com empatia pela vítima, mas também com compreensão pelo perpetrador.

Os negros sul-africanos são o mais recente povo indígena a ter alcançado a emancipação da subjugação histórica, destronando o anacrónico sistema colonial do apartheid, bem como o primeiro povo a alcançar essa revolução através do boletim de voto e não com o cano de uma arma. E, contudo, somos actualmente a segunda sociedade mais violenta no mundo, com uma taxa de assassínios comparável a uma guerra civil de baixa intensidade, com cerca de 50 assassínios por dia ${ }^{2}$, totalizando mais de um quarto de milhão de pessoas criminalmente assassinadas desde que o país alcançou a democracia. A violência contra o Estado, que outrora unia as pessoas, está agora a implodir essas mesmas comunidades.

A criminalidade é indiscutivelmente a nossa questão politicamente mais controversa e emocionalmente penalizada. Têm sido avançadas muitas razões para este flagelo. Certamente, a violência feita à própria cultura pelo regime do apartheid deve desempenhar um papel importante. Continuam a não existir instalações recreativas e culturais para a maioria dos nossos cidadãos. Uma justiça indigena e os sistemas de valores estão completamente destruídos nas cidades.

Não quero com isto sugerir que esta criminalidade violenta seja parte da libertação psicológica. A grande maioria das vítimas de assassínio são negros, especialmente jovens negros. Somente 1 em cada 33 vitimas é branca, mas se fizermos o cálculo disto, aproximadamente 600 brancos são assassinados todos os anos, um cálculo por cada 100.000 que significa que a comunidade branca é ainda objecto da sexta mais elevada percentagem de assassínio no mundo. A comunidade negra tem a segunda maior (depois da Colômbia). Porque é que refiro isto? Porque a maioria dos espectadores de teatro, dos criadores e escritores são ainda brancos e economicamente privilegiados.

0 que distingue os nossos assassínios dos do resto do mundo é o nivel de violência sádica com que são perpetrados. Ainda ninguém conseguiu dar uma resposta satisfatória para isto. Porque é que os assaltantes de bancos, após um golpe bem sucedido e já com o dinheiro na sua posse, ainda se dão ao trabalho de fechar os seguranças dentro da carrinha e queimá-los até à morte? Porque é que, após terem dominado e roubado uma vitima, Ihe infligem uma tortura prolongada? Num caso, obrigando durante duas horas o seu filho e mulher a assistirem à sua tortura. Num outro, derramando plástico derretido sobre as pernas de um homem e depois mergulhando-o num banho de água a ferver. As vítimas são muitas das vezes pessoas frágeis e já idosas. Durante os dias em que escrevi esta reflexão, surgiu nos jornais a notícia de que uma mulher de 90 anos tinha sido violada por um grupo de criminosos; e uma outra mulher de 77 anos foi violada e esfaqueada até à morte com um garfo de jantar. E estes não são casos isolados ou raros.

Não posso deixar de referir, numa espécie de aparte, o modo como a violência na África do Sul tem tido um impacto directo na comunidade de músicos, de actores e de colegas críticos. Dois dos nossos maiores músicos Taliep Petersen e Lucky Dube - foram assassinados o ano passado. 0 actor Kobus Kelynhans foi esfaqueado com 56 golpes. Talvez tenham ouvido falar do assassínio do jovem actor de 28 anos Brett Goldin, três dias antes de partir em digressão com a produção de Hamlet dirigida por Janet Suzman para Stratford-on-Avon. Sir Anthony Sher viria a fazer um documentário para a televisão sobre este incidente.
Sizwe Banzi morreu (Sizwe Banzi est mort), de Athol Fugard, John Kani e Winston Ntshona, enc. Peter Brook, Centre International de Créations Thêâtrales 2007 (Pitcho Womba Konga e Habib Dembélé), fot. Pascal Victor.

'Entre as mais notáveis, vejam-se A Verdade em Tradução (Truth in Trans(ation), de Paavo Tom Tammi, Michael Lessac e Craig Higgison, 2007, e Ubu e a verdade (Ubu and the Truth Commission), de Jane Taylor e da Hanspring Puppet Company, 1997. 
E, contudo, dado este contexto, o crime violento de uma tal relevância quotidiana ainda não chegou aos nossos palcos. Atrever-me-ia a sugerir que há duas razões: correcção política e pressão comercial. Para quem vive com medo de ser assassinado, qual o interesse de ir ao teatro ver uma coisa imaginada por um dramaturgo sobre algo que ocupa diariamente a nossa mente - quando tomamos as nossas precauções, à noite fechando os portões de segurança, ligando os alarmes, ou no carro, com as portas trancadas e o motor pronto a arrancar, à espera que a barreira eléctrica se feche completamente? Muitos dos meus concidadãos sul-africanos preferiam certamente assistir a enforcamentos públicos, em termos de entretenimento, do que ver um homicídio simulado numa peça. Tal como Charles Nonon, o director do teatro do horror parisiense, Le Grand Guignol, explicou quando aquele teatro fechou as portas após 65 anos de actividade: "Nunca conseguiriamos igualar Buchenwald". ${ }^{3}$

Ao contrário do cinema, a simulação ao vivo no palco de situações de violência extrema simplesmente não funciona no contexto da nossa realidade vivida. As peças da geração do ecstasy, tais como Comprar e foder (Shopping and Fucking), de Mark Ravenhill, alcançaram um sucesso muito limitado na África do Sul, parecendo até algo insípidas. Mesmo durante o apartheid, os criadores teatrais e os críticos brancos ficavam muitas vezes perplexos com as reacções dos espectadores negros. Um dramaturgo como Athol Fugard construiu toda uma obra empenhada em enervar o regime do apartheid e contribuir para uma consciência de protesto contra a violência do Estado. No palco, um polícia afrikaaner bate com um bastão num indefeso homem negro, enquanto os espectadores negros se rebolam a rir. Eu assisti a isto inúmeras vezes entre 0 público sul-africano. E, contudo, no caso de um insulto racial, digamos um homem branco a limpar a mão depois de cumprimentar um homem Xhosa, será capaz de
${ }^{3}$ Cf. "Outdone by Reality", TIME Magazine, 30 de Novembro de 1962

${ }^{4}$ Estreado no Marke Theatre, Joanesburgo, desencadear apupos e a indignação do público.

Existe uma excepção notável no nosso teatro no que diz respeito à ultra-violência: o jovem dramaturgo negro Mpumelelo Paul Grootboom, conhecido como o "Tarantino das Townships", uma alcunha que ele abjura fora das bilheteiras. Grootboom conquistou a fama com uma peça localizada num bordel em Hillbrow, Cartas (Cards), que incluía nudez e violência ${ }^{4}$. Isso trouxe-lhe a atenção nacional e, mais tarde, um prestigioso prémio de dramaturgia, o Standard Bank Young Artists Award for Drama. A sua mais recente peça, Relatividade: Histórias das Townships (Relativity: Township Stories), desenvolve-se em torno de uma cabana ${ }^{5}$. É um espectáculo muito bem coreografado, mas a história rapidamente degenera numa intriga psicológica cruamente freudiana em busca do "estrangulador do fio dental", seguindo a fórmula previsivel do filme americano de classe B sobre assassinos em série. Há mulheres que são violadas e estranguladas no palco, um polícia corrupto que sodomiza o filho, abortos autoinduzidos e numerosos assassínios violentos. $E_{1}$ contudo, os retratos de violência não têm a mesma qualidade narcisista que muitas vezes encontramos no teatro europeu; os nossos perpetradores são também eles próprios vítimas. Nem os nossos retratos da violência têm a violência masoquista com que nos deparamos na Europa. Grootboom escandalizou a correcção política e, em declarações à imprensa, sempre insistiu na ideia de que o seu teatro é um retrato realista da vida em bairros de lata negros, dominados pelo crime, como os que ele conheceu quando era mais jovem.

Dada a história do país, não é de surpreender que muitos debates nacionais - a SIDA, o Zimbabwe, a criminalidade - sejam obscurecidos pelo racismo, alegações de racismo e uma hipersensibilidade racial de sul-africanos tanto negros como brancos. 0 Presidente Thabo Mbeki acredita que a ligação entre o HIV e a SIDA e a exuberante disseminação do vírus neste país era um modo de o Ocidente caluniar a comunidade negra como sendo promíscua - que os brancos acham que os negros só conseguem "comportar-se para aquilo que foram talhados, destinados a criar uma sociedade consumida pela corrupção, depravação sexual, autocracia e violência criminosa" (Mbeki 2005).

A comunidade artística liberal branca geralmente alinha neste tipo de posições. Acho surpreendente que nunca tenha havido nenhuma produção dramática sobre assassínios de vingança por parte de agricultores brancos, embora esta seja uma questão candente. A violência no palco é habitualmente de brancos contra negros, ou entre negros, raramente de negros contra brancos. Mesmo para o filme Tsotsi, a adaptação galardoada com um Óscar do romance de Athol Fugard, as vitimas foram actualizadas, passando de brancos para negros ricos.

A mais recente peça de Fugard, Vitória (Victory), demonstrava o perigo de racializar a criminalidade ${ }^{6}$. Era sobre um roubo atamancado de um homem branco por um arruaceiro de cor, com um diálogo dominado por expressões como "nós" e "eles", "as promessas do homem branco" e "o rabo do homem branco". A vítima diz ao ladrão de cor que era só uma questão de tempo até "ser a minha vez de me aparecer você ou alguém como você (...) dada a pobreza entre o vosso povo". A caracterização que Fugard oferece do ladrão é singular, porque ele permanece tão desconhecido como qualquer bandido com uma máscara na cabeça. A peça foi lida pelos críticos como o epitáfio do homem branco sobre a África. 


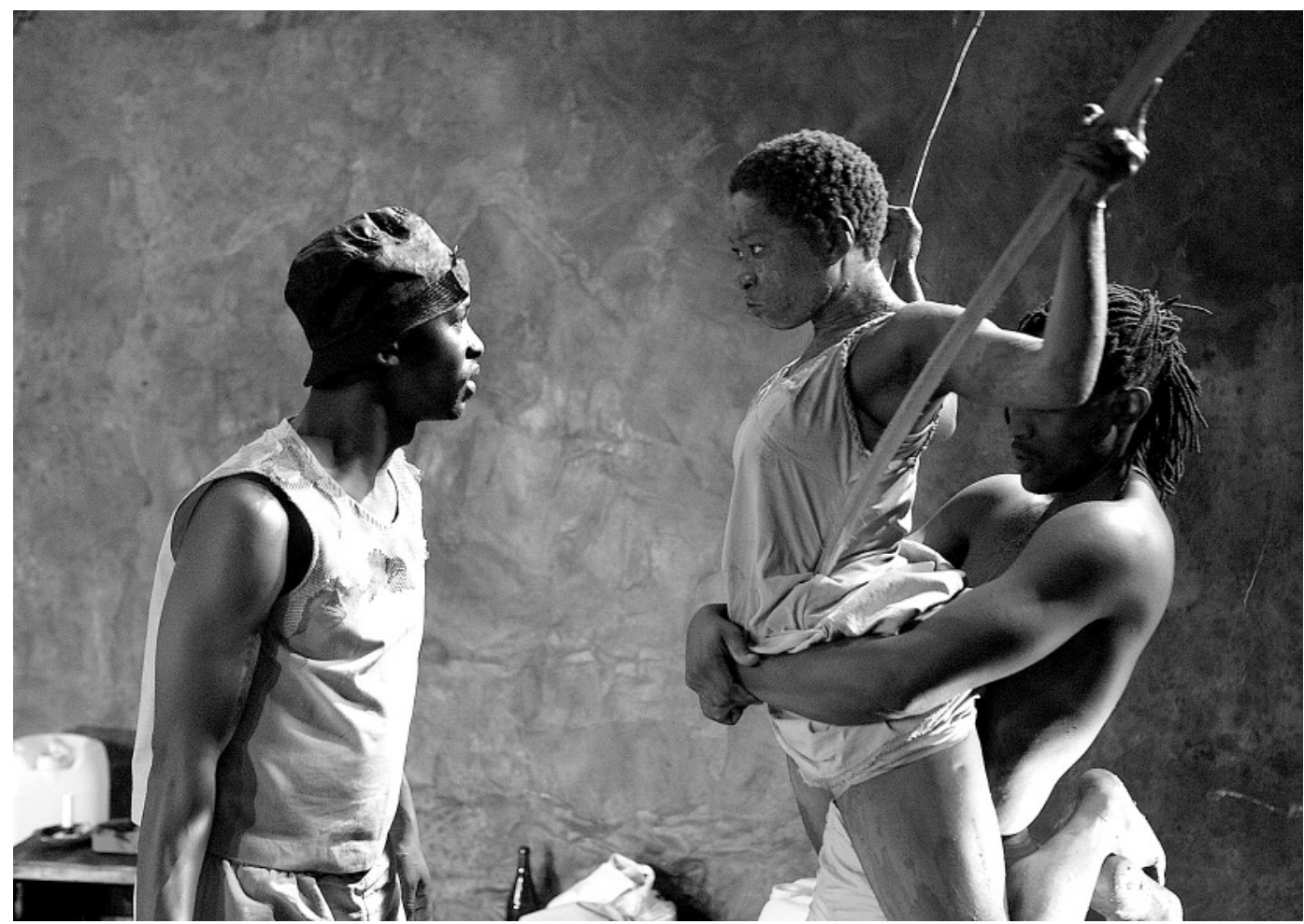

Mas então o crítico pergunta-se a si próprio: como é que devemos retratar a violência numa nova África do Sul democrática?

Penso que uma das respostas mais bem sucedidas é dada pelo criador e encenador Lara Foot Newton. A grande obra de Newton foi uma peça chamada Tshepang sobre actos de violência colectiva num bebé de nove meses numa comunidade remota e empobrecida ${ }^{7}$. Todos os anos, mais de 1.000 crianças são assassinadas, mais de 30.000 atacadas e 20.000 violadas (40\% de todos os casos) ${ }^{8}$.

Tshepang baseia-se num desses incidentes. Seis homens foram erradamente acusados; veio a saber-se mais tarde que o abusador tinha sido o namorado da mãe. A violação é representada através da utilização de um cabo de vassoura e de um pão grande. Trata-se de violência executada com poesia, não com estilização estética. As notas sobre cenografia e adereços referem que estes objectos utilitários permitem evitar o "sensacionalismo potencial" ao mesmo tempo que são envolvidos em acções que alteram "o seu sentido e associações... de acordo com o seu significado na narrativa". 0 "objectivo aqui foi o de criar um espectador envolvido e crítico, mas nunca emocionalmente distanciado" (Newton 2005).

Newton regressou recentemente ao tema da violação infantil em Karoo Moose ${ }^{9}$. A violação é representada com um poder lírico chocante. A jovem rapariga está de pé dentro de uma bacia de esmalte cheia de água, com a rede de uma baliza em cima dela. Nós observamos cada músculo do seu rosto, cada espasmo do seu corpo enquanto ela é usada para o treino de homens que pontapeiam a bola de futebol contra as suas pernas nuas, rindo e festejando à sua volta.

Tal como as pessoas muitas vezes confundem a lascivia com o amor, parece haver hoje em dia uma confusão entre o estilo e a beleza. A beleza desperta o que há de melhor em nós como humanos - pathos e amor. 0 belo e a moral outrora não estavam separados. 0 tratamento poético de actos imorais pode, num espectáculo, ser simplesmente isto. Espectadores e críticos vivem mergulhados na lascivia provocada pelas produções ultraestilizadas, altamente realizadas do "Novo Teatro Europeu" da violência extrema. As criações que, em meu entender, funcionam são aquelas que nunca elevam a violência ao nível voyeurístico, sem perderem nada em termos do horror ou da violência. São inegavelmente realistas em termos de argumento e vão muito mais longe na desmontagem da psicologia tanto da vítima como do perpetrador, pessoa a pessoa, humanidade e inumanidade. $\mathrm{Na}$ África do Sul, pelo menos, a violência consiste em usar a lança para curar as feridas que ela mesmo infligiu.

\section{Referências bibliográficas}

CÉSAIRE, Aimé (1990), "And the Dogs Were Silent", in Lyric and Dramatic Poetry 1946-82, trans. Clayton Eshleman e Annette Smith, The University Press of Virginia.

FANON, Frantz (2004), The Wretched of the Earth [Les damnés de la terre, 1961], trans. Richard Philcox, New York, Grove Press.

MBEKI, Thabo (2005), ANC Today, vol. 5, n. ${ }^{\circ}$ 21, 7 de Maio.

NEWTON, Lara Foot (2005), Tshepang: The Third Testament, Wits University Press.

STEINBERG, Jonny (2007), "Fleeing the cities we inhabit, in whichever ways we can afford", Business Day, 26 de Fevereiro.

WALCOT, Derek (1970), Dream on Monkey Mountain, New York.

Tradução de Paulo Eduardo Carvalho

\footnotetext{
${ }^{8}$ Dados contidos num relatório divulgado em "Shock Child-rape Stats Revealed", Beeld Newspaper, 17 de Maio de 2006. 